\title{
ACTUALIDAD PEDIATRICA.
}

\section{IMFORTANCIA DEL LYSOZYMA EN PEDIATRIA}

\author{
Por el Dr, MARIO GONZALEZ R. \\ Mídico de] Hospiral Roberto del Rio.
}

Siempre había jiamado la atención de los investigadores la resistencia que presentan a las infecciones aquellos tejidos expuestos al medio ambiente. Buscaban su explicación en causas anatómicas, dándole suma importancia a la barrera epitelial; pero ella sola no podia explicar una defensa notoria y eficiente, ya que en a!gunas zonas del organismo el epitelio tiene una escasa estrat.ficación y aun más entre ellos hay abundantes formaciones glandulares a las que no se podría atribuir una función me:ánica de protección. El papel dell mucus secretado en estas glándulas, habría sido únicamente el dè desempeñar ta función física de arrastre hacia el exterior y también el rol de lubricar la superficie epitelíal.

Estos eran los conceptos que Se tenía hasta el año 1922.

Publica entonces Alexandet Fleming (1) un interesantei trabajo en relación con este problema. Demuestra en él que la mayoría de los tejidos y secreciones animales y también algunos vegetales, tientin la propidad de lisar algunas especies saprófitas aisladas del aire.

E1 mismo autor en colaboración con Allison V. D. (2). amplía su trabajo anterior. indicando que las propiedades líticas se deberian a una diastasa que denominaron "Lysozyma". Comprobaton también que esta substancia ejercia su poder sobre varias especies patógenas. Como test det control de actividad de este iermento propusieron un cultivo de sarcinas saprófitas a sladas del aire (Micrococus Lysodeikticus). Demostraron su presencia en diferentes secreciones $y$ excreciones orgánicas, tales como, lágrimas, saliva, semen, suero 
sanguíneo, etc. En proporción muy dievada lo evidenciaron en la clara de huevo.

Continuando sus investigaciones estos mismos autores anuncian en 1924 que enl lysozyma resiste la acción de fermentos tales como la pepsina y la tripsina. Sin embargo su actividad es retardada por la bilis (3).

Posteriormente, J. y M. Bordel (4), encuentran el lysozyma en el calostro y en la leche humana en general, notando con eixtrañeza su ausencia en la leche de vaca.

Rosenthal y Liebermann 15), en 1931, hicieron observaciones sumamente interesantets en relación con este fermento. Se sabía hasta entonces que el intalitino del recién nacido es prácticamente estéril en las primeras 48 horas. Posteriormente venía la invasión de él por la flora bacteriana de aire, y luego una total desaparición de ella para quedar predominando el bacilo bífidus. Esto sucedía al los alimentados a pecho. Estudiaron la presencia de lysozyma en el meconio y no lo encontraron. Lo buscaron al tercero y quinto día y veron que este fermento aparecia en forma sensiblemante uniforme y constance. En los niños alimentados artificialmente con leche de vaca, no lo evicenciaron. así como tampoco encontraron la desaparición de la flora microbiana del aite en sus deposiciones.

Fueron a la experimentación "in vitro" y astablecieron en concluyentes exper"mentos que el lysozyma inhibía en su crecimiento a los bacilos coli y lisaba totalmente: a todos los microbios saprófitos del aire. Este fermento no actuaba sob:e el bac lo bifidus.

Concluyen que el lysozyma contenido en la lecthe humana $y$ que pasa a través del canal intestinal sin alterarse, desempeña un importante rol en la ebtabilización de la flora intestinal del niño alimentado naturalmente, especialmente debido a la inhibición coli y de las bacterias del aire.

Antes de seguir ade!antes veremos lo que se ha investi. gado en otras zonas del organismo.

Amoss y Taylor (6) habían cemostrado que el filtrado de lavado nasal era capaz de inactivat el virus de la poliomielitis. Howitt (7) confirmó más tarde estos resu'tados e hiżo resaitar que la inactivación por el principio nasal es progresiva $v$ relativamente lenta, al revés de lo que sacede con los anticuarpos séricos. Burnet (8) encontró que la secreción nasa! era activa sobre los $\mathrm{v}$ rus tino influsnza y herpes. Francis $(9)$, como conclusión general dice que e! mucus 
nasal ejerce su acción sobre todos aquéllos virus sensibles al desoxicolato sódico.

Prickett P. S., Miller N. J., Mc. Donald F. (10), notaron un aumento de lysozyma en los tejidos de ratas sometidas a dieta deficientel en vitamina $A$.

Nicholas P. Sullivan e Ira A. Manville (11), estudiaron en conejos la relación existente entre las deficiencias vitamina $A$ y ácido úrico, por una parte, y el contenido lysozymico de los tejidos.

Titularon el lysozyma contenido en las diferentes partes del tracto gastro intestinal y comprobaron que el colon es mucho más rico en este principia lítico que los demás segmentos; el colon de conejos carentes en vitamina A demostró tener dos a cuatro más lysozyma que el colon normal. Indicándole una dieta rica en vitamina $A$ y ácido úrico se obtuvo la normalización. Los autores concluyeron en su trabajo que la vitamina $A$ y el ácido úrico tienen gran importancia en la secreción de! lysozyma del tubo digestivo $y$ que los animales carentes en esta substancia aun cuando producen lysozyma no pueden aprovecharla.

Anderson (12) observó la disminución de contenido 1ysozymico en las lágrimas de animales y personas catentes en vitamina $A$ y demostró que la xeroftalmia podía ser curada con tratamiento local con lysozyma.

Carl E. Cahn v Bronner M. D. (13), investigando el contenido lysozymico en el mucus nasal de individuos normales observaton que en un mismo individuo habia variaciones notables entré un día y otro. y al mismo tiempo un hecho digno de recalcar es aue en los cuatro primeros días del resfrío común el contenido lysozymico nasal llëga a desaparecer y también demostraron aue el lysozyma aumenta en las afecciones alérgicas de esta región.

Entre nosotros, es en la Cátedra del Prof $\mathrm{H}$. Vaccaro. donde se han dado a conocer las más interesantes invebtigaciones con este fermento. Se destacan las de Rubina (14), quien investiga algunas properlades químicas de este fermento. Pone en evidencia que los compuestos sulfamidados puestos en contacto con alpunas substancias que contienen lysozima en gran cantidad tal como la clara de huevo no altetan su poder lítico v por el contrario patecen reforzar su acción.

A. González (15), demuestra también la acción bacteriolítica de la secreción nasal la sarcina test, el estafilococo apatógeno, estreptococo viridans y estafilococo patógeno. Demuestra también que el diplococo neumónico es resistente 
al lysozyma. Hace resaltar también el alto poder Iysozymico de los senos paranasales y observa la franca disminución de él en los procesos inflamatorios de estas cavidades. Corrobora, además, las afirmaciones de Cahn y col. referentès al aumento del contenido lysozymico en las afecciones alérgicas de esta zona.

Copaja (16), bacel un interesante estudio del contenido lysozymico en las deposiciones del recién nacido $v$ lactante y demuestra la influencia que este fermento tiene en la flora intestinal del niño.

Ptopiedades y mecanismo de acción de lisozyma.-. Fleming (2), adelantó la hipótesis de que el lysozyma fuera una substancia de naturaleza enzimática sin que lograra demostrar esta aseveración.

Hallauer (17), siguiendo al anterior, supone que esta acción diastásica se ejercería sobre una fracción mucoidea de las bacterias. Analiza su acción en la sarcina test y concluye que su lisis va acompañada de desprendimientos de $N$ no proteico y $\mathrm{P}$ inorgánico $\mathrm{y}$ de un grupo de substancias reductoras provenientes dell protoplasma microbiano.

Meyer y col. (18), tratando de averiguar el mecanismo de acción de este fermento pensaron que su actividad lítica podría deberse a un mecanismo físico-químico, principalmente pot modifinciones en la tensión superficial por las experiencias realizadas concuerdan en que ella no desempeñan papel alguno en su mecanismo de acción. Concluyen también en que el lysozyma carece totalmente de actividad proteasa, kinasa. amilasa, lipasa $v$ fosfatasa. Deducen ellos que la acción del lysozyma se ejerce sobre uno de los eslabones azucarados de ciertos mucoides cuya naturaleza es desconocida, comparan su acción al de la diastasa sobre el almidón en su primera eltapa,

Epstein y Chain (19), llegan a la conclusión que el iysozyma es un fermento que hidrolisa a un polisacarido insoluble en agua y que fotma patte del cuerpo microbiano de las especies sensibles; la desintegración de él iría acompañada de lisis completa de las bacterias, pues sería un elemento esencial en su estructura morfológica. Cuando el enzymo actúa como bacteriostático o bactericida, suponen ellos que el polisacarido es desintegrado parcialmente, y si lo es en su totalidad no se produce la lisis por existir otros elementos que mantienen la estructura. La acción bactericida sel explicaría por ser el polisacarido un elemento de vital importancia en 
$\vec{e} 1$ metabolismo intermediario de los agentes microbianos. Sería entonces el lysozyma una carbohidrasa.

Numerosos autores han tratado de obtener la substancia al máximum de pureza. Entre ellos el que ha hecho un estudio más completo es Abraham (20), quien logtó obtaner un producto amorfo y otro cristalizato cuya actividad era más o menos semejante, alrededor de 2,000 unidades por mgr., según el método det Florey. En la parte amorfa puso en evidencia diferentes animo-acidos tales como: arginina. cistina, lisina, tirosina e histidina.

Meyer y col. (18), obtuvieton un lysozyma sumamente puro y encuelatran que es un cuerpo de naturaleza básica. soluble en metio acuoso acidificado, insoluble en medios alcalinos y disolventes orgánicos puros. Su peso molecular fué alrededor de 25,000.

Es una substancia muy resistente al calor y también a los ácidos, sin embargo actúa mejor en medios neutros (Rubina). Se comporta como un coloide electro-positivo. Se destruye por los rayos ultravioleta. Sus soluciones conservan su activioad por mucho t'empo tanto al frío como a! calor.

Rubina. demostró que el jugo gástrico normal no altera el poder lítico del lysozyma. Fleming y Allison. demuestran la gran importancia que tienen las concentraciones salinas en la bacteriolisis, favoreciéndose enormemente en las concentraciones bajas.

Algunos investigadores han óudado que el fermento descubierto en los diferentes humores del organismo sea un mismo principio. Thompson (21) después de realizar un estudio detallado cree justificado incluit a todos esos agentes líticos en el término de lysozyma.

Fuentes de origen de lusozuma.-Bordet (4) demostró la presencia de lysozyma en el sudor humano y también demostró cue la sangre coagulada lo contiene en muy pequéña prcporción. no así la citratada. que lo contiene en alta cantidad.

Gavaers (22). demostró la presencia de lysozyma en las secreciones yaginales y en los loqu'os.

En las secreciones vaginales patológicaus existe lysozyma. pero en muy escasa proporción (Cátedra de! Prof. Vaccaro).

Prickett y col., evidenciaron el lysozyma en ciferentes leches de mamíferos, tales como: en la humana, de mona. gata, perra y llama. Un título mucho menor dimostiaron tener la leche de cabra. oveja, cuyes. 
En resumen, el lysozyma es ina substancia probablemente una diastasa (carbohidtasa), quel se encuentra en los diferentes humores del organismo (lágrimas, sudor, leche). Se lel han descrito a él propiedades lítico-nhibidoras sobre diferentes cepas microbianas siendo dignas de recalcar aquella que ejerce sobre el bacilo coli y sobre las éspecies microbianas saprófitas del aire. Es una substancia cuya presencia en la leche humana es absolutaments constante, resistente a los jugos digestivos. se elimina por las deposiciones de los niños alimentados al pecho. encontrándosele duranté toda la lactancia. No se le encuentra en las heces de los niños alimentados artificialmente y tampoco en la leche de vaca. No ejerce poder lítico inhibidor sobre el bacilo bífidus. Su activ:dad els máxima en los medios neutro. con concentraciones saIinas bajas.

Ai parecer existe una relación entre 4 lysozyma y la vitamina $A$, ya que es evidente su disminución en la xeroftalmina, curando esta afecc ón, con la aplicación local de substancias que contengan alto poder lysozymico.

E1 1ysozyma actúa sobre algunas cepas microbianas lisándolas. en cambio actúa sobre otras ejerciendo simp'emente un poder inhibidor.

De las experiencias de Nets: (23), se desprende que ningún solfonamido altexa las propiedades liticas del lysozyma y la acción lítica conjunta dél dysozyma y de los compuestos sulfamidados es superior a la acción que ejerce cada uno de estos compuestos por parado.

\section{BIBLIOGRAFIA}

1--FLemiNG A. - Proc, Roy. Sac Garies B. XCLI: 315.1922.

2. FLEMING A. AdLLON V. D. - "Obervations on the Bacteriolycic

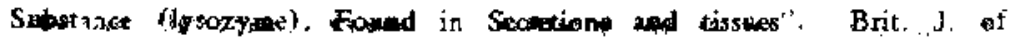
Exp. Pacho:. HI: 252, 1923..

2.-FLEMING A., ALiLSGN V. D. - Proc, Roy, Sac. London S, B. 94: 142.1923 .

3.. FLEMING A., AI.LISON V. D. - "On the anibacterial power of egg-winte". The lanset. 1: 1305-7. VI, 1924.

4.-BOR[ET' J. - " "Contribution a letude du lysozyme". Comptes rendus d. la soc. de Biol. 4: 1252, 1928.

4.-BOREJE'T J. -- Truté de İinmunité. 256. 1939.

5.-ROSENTHAL L.. I.IEBERMAN H. - "The rale of lysozyme in the development of the intestinal flora of the new-born infant". Jours. of Infect. Diseters. $48:$ N.9 2: 226. 1931. 
6.-AMOSS y TAYLOR - I. Exper. Med. 25: 507. 1917.

7.-HOWITT. - J. Infect., Dis.. 60: 113. 1937."

8.-BURNET. - Brit. I. of Expert. Pstbol. 28: 377.1939.

9-FRANCIS. - Science, 91: 198.. 1940..

10.-PRICKETT P. S., MILLER N, J., MAC DONALD F, - "The ly. sozyme content milk from various apecies and its relation to the fical flora of their nursiziz". J. of Bacteriology. 25: 61. 1933..

11 -SULLIVAN N. P., MANVILLE I. A. - Relatioschich of diet sebf regalatoty defense mecbanism, lisozyme in vitamin $A$ and in uronic as. Geficintes. Am. J. Pab. Healtb, 27, 1108-15-37.

12-ANDFRSON, - Uberdie verhanltuise des lysozyme be rerophalmie. Acta Paediat. 18, 81. 1932.

13.-CAFIN C. BRONNER M. D. - La presenciz y acción del lysozyma de la mutasa nasal. Annals of Ocology, Rhinology and Laringology. 51: LiL, 1942.

14.-.-RUBIRA M. - Contribución al estodio de lysozyma. Tesis 1942.

15. -GONZMLEZ $R$. El lysozyma como factor de deffensa en Ototrinolaringologia. Tesis 1943.

16. COPA.A. - Importancia del lysozyma en el tractus digestivo en el recién, nacido y ent $\mathrm{e}^{1}$ lactante. Tesis 1943.

J7.- HALI AUER G. - Zentr. Bakt. 1 Abt. Orig. 114:519. 1929.

18.-MEYER K., PALMER J., THOMPSON R, - Sobre el mecanismo de aceión del lysozyma. J. Biol. Cbem. 113; 479-486.. LLL.. 1936.

.Purificación y propiedades del lysozyma, J. Biol, Chem, 113: 209-9. 1936.

19 --EPSTEIN y CHAIN. - Algunas observaciones sobre la preparación y propiefades del sustraram del bysozyma. Brit. J. of Exper, Pathol. 2l: 339. XLI-1940.

20.-ABRAHAM E. P. - Algnas propiedades del lysozyma de la clara de huevo. Bioch. Joumal. 33: 622. 1939.

21.-THOSAPSON R. - El lysozyma y sus relaciones con las propiedades antibacterianas de varios tejidos y secreciones. Arch. Patbol. 30: 1096. 1940.

22.-GOVAERTS, - Cit. por A. González (15).

23.-NETER. - Cit. por M. Rabina (14). 